$A \mathbb{N R A} \mid$

Documentos e Debates
Disponível em

http://www.anpad.org.br/rac

RAC, Curitiba, v. 15, n. 2, pp. 320-332, Mar./Abr. 2011

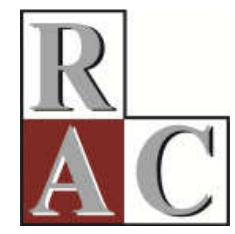

\title{
O que é um Ensaio-Teórico?
}

\author{
What is a Theoretical Essay?
}

Francis Kanashiro Meneghetti *

E-mail: fkmeneghetti@gmail.com

Universidade Positivo - UP

Curitiba, PR, Brasil.

* Endereço: Francis Kanashiro Meneghetti

Rua Professor Pedro Parigot de Souza, 5300, Prédio da Biblioteca, $5^{\circ}$ andar, sala 11, Curitiba/PR, 81280-330.

Copyright (C) 2011 RAC. Todos os direitos, até mesmo de tradução, são reservados. É permitido citar parte de artigos sem autorização prévia, desde que seja identificada a fonte. 


\section{O que é um Ensaio Teórico?...}

"Quando brinco com minha gata, quem sabe se ela não está se divertindo mais comigo do que eu com ela?" (Montaigne, 2002, p. 3). Este é o espírito do ensaio-teórico ${ }^{(1)}$, a relação permanente entre o sujeito e objeto, um vir-a-ser constituído pela interação da subjetividade com a objetividade dos envolvidos. Neste contexto, o ensaio, desde a época de Montaigne, "se tornou uma forma respeitável; sua novidade estava na louvação do eu. Sua razão de ser era a noção de que os pensamentos, sentimentos, incertezas, certezas e contradições de uma pessoa merecem divulgação e em seguida atenção de outras" (Boorstin, 1995, p. 697). Da época de Montaigne até a atualidade, os ensaios adquiriram diversas formas e formatos, assim como são utilizados para diversos fins: literários, filosóficos, científicos etc. Essas variações nas formas e formatos, assim como a multiplicidade nas suas utilizações, levam a concepções e usos equivocados desse estilo e forma de refletir a realidade. Diferente do método tradicional da ciência, em que a forma é considerada mais importante que o conteúdo, o ensaio requer sujeitos, ensaísta e leitor, capazes de avaliarem que a compreensão da realidade também ocorre de outras formas.

Este ensaio deve ser lido por sujeitos com espíritos livres de preconceitos, sem estarem dominados pelo formalismo da ciência. Aqui o leitor não encontrará a disposição formal de um estudo que segue a divisão e a lógica estabelecida pelas metodologias científicas tradicionais. No lugar do objetivo geral, dos objetivos específicos, da justificativa, da fundamentação teórica, da metodologia que define os critérios de coleta e análise de dados e da conclusão, no ensaio a orientação é dada não pela busca das respostas e afirmações verdadeiras, mas pelas perguntas que orientam os sujeitos para as reflexões mais profundas. Assim, respeitando a concepção original do que é ensaio, este necessita de leitores preparados para compreender a sua importância para a formação do conhecimento na atualidade. Basta lembrar que o empirismo, o racionalismo, o positivismo e tantos outros conhecimentos que sustentam a base da ciência tradicional de hoje surgiram por meio de vários ensaios de pensadores e intelectuais. Logo, as perguntas fundamentais que orientam este ensaio são: que é e quais as características, como se dá a construção, quais os elementos presentes no movimento de construção, quais as relações entre o ensaio e a administração de um ensaio?

Para os leitores mais tradicionais, que esperam conclusões por meio de afirmações definitivas, a orientação é que cessem a leitura neste momento. As reflexões no decorrer do ensaio instigam os leitores a tirar suas próprias conclusões. Para aqueles que gostam de desafios e provocações que levam a livres reflexões e conclusões, a aventura começa agora. Da época de Montaigne até a atualidade, os ensaios tornaram-se importantes formas de geração de conhecimento. Várias são as áreas que os utilizam como forma: da ciência física à literatura, passando pela filosofia, pelas ciências sociais, pela química e pela biologia; o ensaio é forma que quebra a lógica esquemática e sistemática da ciência tradicional, sobretudo de natureza positivista. Os ensaios são muito utilizados na área das ciências sociais. Grande parte dos cientistas sociais, políticos e sociólogos utilizam-se da forma ensaística para produzir reflexões sobre os acontecimentos mais relevantes da sua época. A forma ensaística consolidou vários autores conhecidos como Marx, Weber, Norbert Elias, etc. No Brasil, Raimundo Faoro, Darcy Ribeiro, Antonio Candido, são nomes importantes que se utilizaram do ensaio para refletir sobre a formação social no Brasil. Apesar das contribuições expressivas nas áreas econômicas, ciências sociais, economia etc. nenhuma área do conhecimento utilizou tanto o ensaio como a Filosofia, sobretudo os filósofos iluministas. Alguns exemplos são referências; entre eles destacam-se: Rousseau (1973) com o Ensaio sobre a origem das línguas; Locke (1997) com o Ensaio acerca do entendimento humano; Hume (1996) com sua Investigação acerca do entendimento humano. Posteriormente, outros filósofos utilizaram o recurso do ensaio para pensar e experimentar a realidade, como Bachelard (1998) e Habermas (2001), por exemplo.

Ante tantos ensaios, é possível definir o que é ensaio? Que há de comum nos ensaios das diversas áreas de conhecimento, se realmente existe alguma coisa em comum entre eles, que possa definir o que seja a essência do ensaio? 
O fato é que "os maus ensaios não são menos conformistas do que as más dissertações" (Adorno, 1986, p. 170). Sua força, apesar de não estar atrelada ao rigor metodológico, como acontece na produção científica, está na capacidade reflexiva para compreender a realidade. Em tempos de especialização crescente do conhecimento, da velocidade, como novas técnicas são criadas, novas estruturas racionais são apresentadas e uma indústria cultural e intelectual faz com que a atualidade do ensaio seja anacrônica. Há associação indevida do ensaio como produtor de conhecimento estruturado, devido à expansão da produção de informações e pseudoconhecimentos, incentivados pela indústria cultural e intelectual. Assim,

a forma do ensaio até hoje ainda não percorreu o caminho da autonomização que a sua irmã, a poesia, há muito já deixou para trás: desenvolver-se a partir de uma primitiva unidade com a ciência, a moral e a arte (Lukács, 1911, p. 29).

Muitos ensaios, na atualidade, tornaram-se uma embalagem que privilegia a forma, que atende ao produto que se almeja entregar. Como embalagem que envolve um produto, seja na forma de presente ou de mercadoria para consumo cotidiano, sua qualidade pode ser manipulada por quem vende, quem ganha ou compra o produto. É possível dar um presente (de conteúdo) ruim, duvidoso na qualidade, questionável em relação à originalidade, mas que pode ser valorizado pela embalagem: forma da escrita, ortografia, frases de efeito etc. Muitos indivíduos apelam para o ensaio, porque neste parece caber tudo. Todo conhecimento é possível, a falta de rigor nas argumentações são mascaradas com a ideologia da liberdade total. Muitos ensaístas criticam a forma como a ciência gera novos conhecimentos, não pela crítica em relação ao processo científico, pela metodologia utilizada ou pelo formalismo da ciência, mas porque se agarram no ensaio como forma, por considerarem mais fácil e prático fazê-lo.

O ensaio precisa ser utilizado como opção consciente e intencional, ou seja, como a forma mais adequada no entendimento de algo. O que se verifica, na atualidade, é que o ensaio vem atender a um apelo da sociedade do consumo cultural e midiática: Vale tudo para se expressar. A utilização do ensaio como forma não significa a total rendição ao fim dos limites formais ou a crítica irracional que se possa fazer em relação à ciência, mas uma forma específica de compreensão da realidade, por meios diferentes daqueles utilizados pela ciência, na sua forma tradicional de produzir conhecimento. Assim, o ensaio caracteriza-se pela sua natureza reflexiva e interpretativa, diferente da forma classificatória da ciência. No centro do ensaio está a relação quantitativa versus qualitativa. Enquanto a ciência adquire maior autonomia, valorizando aspectos quantitativos para promover generalizações que façam com que um número cada vez maior de pessoas passe a compreender o mundo a partir da instituição de uma racionalidade baseada na calculabilidade, o ensaio valoriza aspectos relacionados às mudanças qualitativas que ocorrem nos objetos ou fenômenos analisados pelos ensaístas. Na essência dessa relação, "o ensaio é a forma da categoria crítica de nosso espírito, pois quem critica precisa necessariamente experimentar, precisa criar condições sob as quais um objeto se torne visível de novo e diversamente do que num autor" (Bense, 1947, p. 420). A forma como o ensaísta experimenta, especula e vivencia o objeto só se torna possível na compreensão qualitativa dele. Abre-se mão das simples classificações e quantificações que possam criar categorias generalizáveis para o entendimento humano compartilhado. Nos ensaios, "o álacre e o lúdico são-lhe essenciais" (Adorno, 1986, p. 168). Sua lógica foge à racionalidade instrumental ou à calculabilidade do mundo moderno. A separação entre ensaio e ciência, na atualidade, ocorre por motivos diferentes da época do Iluminismo ou do início do Século XX. Enquanto a ciência caminha para a objetividade cada vez maior, o ensaio, nas mãos dos falsos ensaístas, cai muitas vezes em processo de subjetivação. Na atualidade da indústria cultural, a ciência e a forma ensaística se confundem, quando ambas se tornam meios e não fins em si mesmos, ou seja, quando são utilizadas como instrumentos de dominação e de reprodução da lógica econômica ou das racionalidades dominantes. Adorno, qualificando o ensaio como forma de arte, percebe que a "separação entre ciência e arte já é irreversível. Só a ingenuidade do fabricante de literatura, que, no mínimo, se considera um gênio da organização e converte boas obras de arte em má sucata, não toma conhecimento disto" (Adorno, 1986, p. 170). A ciência e a arte e, consequentemente, o ensaio separam-se com o progressivo processo de objetivação do mundo. O ensaio como forma atende aos interesses do mercado, não restritos apenas às relações econômicas, mas também à simples 
utilização dos ensaios como recursos ou meios para obtenções de vantagens ou ganhos individuais. Na área acadêmica, os ensaios tornaram-se formas facilitadas de produção considerada científica, sobretudo nas áreas das humanidades ou das ciências sociais aplicadas, incluindo administração, teoria das organizações etc.

A suposta facilidade de apenas sentar e escrever, ante a necessidade de tempo, empenho, trabalho extra além da escrita ou realizar entrevistas, aplicar questionários, tabular e outros, muito comuns nas produções de caráter científico, faz com que muitos pesquisadores se aventurem nos ensaios. Grande parte desse movimento ocorre devido ao produtivismo crescente. A exigência cada vez maior de pontuar, dentro da lógica das agências reguladoras da área científica, faz com que os pesquisadores procurem meios para serem cada vez mais produtivos. Neste contexto, o ensaio parece ser o meio mais fácil. Todavia, existem contradições nesse processo: primeiro porque, conforme a ideia de Adorno já apresentada, os maus ensaios são tão ou mais danosos do que as más dissertações, ou outras formas de produção do conhecimento. Segundo, um ensaio teórico exige maturidade do ensaísta como atender a quesitos específicos que o qualificam. Muitas dessas características exigem empenho e compromisso por parte dele, o que não é diferente da situação em que se está produzindo dentro dos critérios científicos. Terceiro, os bons ensaios são reflexões profundas e minuciosas. Para tanto é exigido envolvimento, reflexão e capacidade analítica e crítica no pensar e repensar em relação ao ensaio proposto. Diferentemente dessas condições, "em relação ao procedimento científico e à sua fundamentação filosófica como método, o ensaio, de acordo com sua própria ideia, tira todas as consequências da crítica ao sistema" (Adorno, 1986, p. 173). Conforme o parecer de Adorno (1986, p. 173), "mesmo sem dizer isso expressamente, o ensaio se conscientiza quanto a não-identidade; radical no não-radicalismo, na abstenção diante de qualquer redução a um princípio, no gesto de acentuar o parcial diante do total, no caráter fragmentário".

O ensaio é um meio de análise e elucubrações em relação ao objeto, independentemente de sua natureza ou característica. A forma ensaística é a forma como são incubados novos conhecimentos, até mesmo científicos ou pré-científicos. Não é instrumento da identidade entre sujeito e objeto, mas é meio para apreender a realidade, por renúncia ao princípio da identidade. Assim, surge como tentativa permanente de resolver a questão central da filosofia moderna: a separação e tensão permanente entre sujeito e objeto na compreensão da realidade. Sua radicalidade está no seu não-radicalismo dogmático. A radicalidade estabelece-se na forma como o ensaísta vai à raiz do objeto analisado. Assim, a radicalidade é ir à raiz sem dogmatizar em métodos ou sistemas fechados na compreensão dos objetos. Desta maneira, o ensaio não segue a mesma lógica da ciência tradicional ou das teorias sistematizadas. Conforme afirmação de Spinoza e lembrado por Adorno, "a ordem das coisas seria a mesma que a das ideias. Já que ordem sem lacunas dos conceitos não se identifica com o ente, o ensaio não almeja uma construção fechada, dedutiva ou indutiva" (Adorno, 1986, p. 174). O ensaio não requer um sistema ou modelo específico, pois seu princípio está nas reflexões em relação aos próprios sistemas ou modelos. Permite a busca por novos enfoques e interação permanente com os próprios princípios da forma. No ensaio, busca-se a construção da forma adequada, mesmo que esta não exista a princípio. Nele, o objeto exerce primazia, mas a subjetividade do ensaísta está permanentemente em interação com ele. A subjetividade é dos elementos permanente e importante na forma como o ensaio avança como processo de conhecimento. A verdade não se concretiza pela afirmação dogmática resultante da simples utilização de modelos ou sistemas. A verdade é reduzida a meio, não confundindo verdade com princípio da identidade. Desta forma,

se a verdade do ensaio se move através da sua inverdade, então ela não deve ser buscada na mera antítese de seu componente insincero e proscrito, mas nele mesmo, em sua mobilidade, em sua falta de solidez, cuja exigência a ciência transferiu das relações de propriedade para o espírito (Adorno, 1986, p. 184).

A verdade não se torna propriedade da consciência e não é apropriada como resultado de procedimentos estabelecidos. Ela se orienta pelo processo permanente de fragmentação dos seus próprios pressupostos. A característica mais elementar do ensaio é a originalidade. $\mathrm{O}$ entendimento deste está relacionado à concepção de novidade. $\mathrm{O}$ ensaio precisa ter algum elemento de originalidade, associado ao ineditismo. Assim, precisa ter algo incomum, nunca visto, publicado ou impresso. A 
originalidade pode estar na argumentação, na escolha do objeto de análise, no recorte dado à análise, na abordagem epistemológica, na subversão da racionalidade dominante, relacionada ao tema. Em muitas situações, o ensaio está relacionado ao novo, ao ecletismo ou ao fora de padrão. Assim, este é mais do que a concepção atribuída por Lukács (1911, p. 23), para quem

o ensaio sempre fala de algo já formado ou, na melhor das hipóteses, de algo que já tenha uma vez estado aí; pertence, pois, à sua essência que ele não destaque coisas novas a partir de um vazio nada, mas se limite a ordenar, de um modo novo, coisas que em algum momento já foram vivas.

Este entendimento limita-se aos ensaios literários, área de Lukács.

Em relação à originalidade na argumentação, o ensaio tem como atributo sair da razão e da argumentação padronizada. A linha de raciocínio argumentativa não deve render-se ao mero formalismo da lógica tradicional. A compreensão dos argumentos precisa estar embasada em pressupostos válidos, verificáveis ou não, pois se somente os pressupostos verificáveis tivessem validade, o ensaio se reduziria à comprovação mecanicista da realidade. $\mathrm{O}$ ato argumentativo precisa ser construído ao longo do processo de envolvimento com o objeto. Os argumentos são resultados da interação de sujeito e objeto, em que a lógica e as verdades são meios e não fins em si mesmos. A argumentação não deve caracterizar-se como busca desmedida da verdade. A verdade, como fim em si mesma, é responsável por retirar a originalidade da argumentação exigida no ensaio. Isto ocorre porque, se a verdade existisse em si mesma, o componente essencial da originalidade não poderia existir, já que toda a originalidade pressupõe surpresa em relação à compreensão tradicional de algo. A argumentação é a rendição do princípio afirmativo de algo, e a permanente renúncia às respostas prontas, previamente apresentadas como forma de solucionar os questionamentos. Esta é a razão em movimento, em que a verdade é apenas o momento em que algo parece ser resultado de uma certeza ou da existência de um elemento definitivo. A originalidade da argumentação consiste em consolidar o movimento da dialética, em que o ato racional da argumentação é o motor do movimento que transforma a compreensão da realidade. A originalidade da argumentação consiste em achar elementos novos e diferentes dos tradicionalmente apresentados, ou seja, é nova razão, prova, demonstração ou indício que modificam a compreensão qualitativa do objeto, contudo sem fazer do próprio argumento uma verdade em si mesma. São Tomás de Aquino afirma que o argumento é o que convence a mente a assentir em alguma coisa. Entretanto, a coisa (objeto) está em movimento, assim como a mente do ensaísta, o que leva à necessidade de revisar permanentemente os elementos de convencimentos que levaram ao assentimento. $\mathrm{O}$ argumento não deve ser ato de fé, de renúncia da razão questionadora. Tampouco deve ser o que Locke (1997), no livro Ensaios, entende como sendo um argumento: a forma de fazer com as provas sejam capazes de fazer com que uma proposição passe a ser verdadeira. A originalidade da argumentação não pode render-se a essa concepção, porque, se assim fosse, a argumentação seria reduzida a uma utilidade antecipadamente estabelecida ou a uma vontade previamente definida antes mesmo do desenvolvimento do argumento. O argumento, por si só, é um ato, em que as razões são transformadas pelo processo permanente de revisitar a própria razão e em que verdades são colocadas à prova. Outra característica relevante no ensaio está associada à escolha do objeto de análise. Este é a coisa que se manifesta na forma de fenômeno a ser compreendido. $\mathrm{O}$ objeto pode ser material ou imaterial, concreto ou abstrato, mas sempre é real, pois existe enquanto algo que aparece, possui essência e é cognoscível na totalidade. De um objeto podem derivar outros, porque, como fenômeno, pode manifestar-se de diversas formas. No ensaio é possível experimentar os objetos no intuito de compreender os fenômenos que os acompanham. O ensaio permite a tentativa de compreender o fenômeno para conhecer o objeto, assim como permite analisar o próprio fenômeno para modificar a compreensão do objeto. As escolhas dos objetos não estão associadas às escolhas deliberadas da razão, baseadas na identificação das coisas previamente previstas. Os objetos podem ser identificados no próprio desenvolvimento do ensaio, ou seja, é possível que um ensaio comece com um objeto definido ou mesmo sem um e chegue ao fim com o mesmo objeto, com outro, ou ainda com nenhum objeto analisado. O fato é que as escolhas destes podem, ou não, ser intencionais, antecipadamente previstas ou não; mas é fato, que mesmo a total ausência de um objeto já caracteriza a existência de um objeto, o nada. 
O mais comum, no entanto, é atribuir um objeto de análise já no início do ensaio. Ocorre que o processo de análise só é possível na manifestação do objeto como fenômeno. O ponto central está na compreensão do fenômeno, levando em consideração que o fenômeno é aquilo que se apresenta; a separação entre essência e aparência é uma consequência natural. Por mais que o pensamento tente compreender e abarcar a totalidade da realidade, é fato que a consciência não consegue realizar esse empreendimento. Assim, conforme Marx afirma, se a essência fosse igual à aparência, a ciência inteira não existiria. Analogamente, se o objeto fosse igual ao fenômeno, não seria possível a formação da consciência. A compreensão do objeto requer escolhas de ordem epistemológicas. Elas não implicam cair no dogmatismo da epistemologia escolhida. A experimentação de epistemologias diferentes para analisar o objeto requer cuidados para evitar que implicações lógicas não sejam totalmente divergentes, de tal forma que inviabilizem a compreensão mínima do objeto estudado. Incongruências de pressupostos e de fundamentos básicos precisam ser evitadas. Todavia, as possíveis contradições que a experimentação de epistemologias diversas, associadas de forma interdisciplinar, são aceitas como normais dentro dos ensaios. Conversas entre epistemologias diferentes encontram no ensaio um campo fértil, sobretudo pela natureza de experimentação. Observando o positivismo, a fenomenologia, parte do materialismo histórico, o pragmatismo e o estruturalismo, percebe-se que seus fundamentos surgem e se consolidam muito em função de ensaios apresentados por seus idealizadores e seguidores. $\mathrm{O}$ fato decorre da eminente a necessidade do salto indutivo, que todo o novo conhecimento precisa realizar para reformular e apresentar seus pressupostos e alicerces. O ensaio é a aproximação das partes, sem que, necessariamente, esteja acompanhado da obrigatoriedade de escrever sobre o todo. A totalidade, mesmo que inerente ao objeto, não requer a compreensão consciente, ou sistematizada de forma cognoscível, isto porque quem "escreve ensaisticamente [é] aquele que compõe experimentando; quem, portanto, vira e revira o seu objeto, quem o questiona, apalpa, prova, reflete" (Bense, 1947, p. 418). Assim, o ensaio aproxima-se do objeto pelo princípio da não-identidade ${ }^{(2)}$. Sua forma de compreender a realidade é sempre não dogmática. É meio, sem cair no relativismo das epistemologias que negam a possibilidade de conhecer a realidade. $O$ ensaio é a busca pela compreensão do objeto, sem que nele haja um sistema de compreensão rígido. É a forma como a realidade é questionada pela razão que questiona a própria razão. Apesar dessas características, o ensaio não tem caráter fragmentário ou atua como mero instrumento de especulação motivada pela razão. Implícita na crítica ao ensaio de que ele seria fragmentário e aleatório, está a crença na totalidade, enquanto imediatamente dada na acessibilidade do todo que, por sua vez, implica a identidade - pelo menos potencial - entre sujeito e objeto, pedra de toque de toda tradição filosófica ocidental. "O pensamento adquire sua profundidade em função do seu grau de penetração nas coisas, e não na profundidade da relação que ele estabelece entre elas e algo diferente das mesmas" (Duarte, 1997, p. 77).

O "ensaio obriga a pensar a coisa, desde o primeiro passo, em tantos níveis distintos quantos nela existem, sendo assim um corretivo daquela rígida primitividade, que sempre se associa à ratio corrente" (Adorno, 1986, p. 179). O ensaio pode ou não se utilizar da razão corrente, mas nunca se associa a ela como ato de conformismo. A razão corrente não deve ser um meio apenas para construir logicidades ou estruturações sedimentadas da consciência. A razão corrente precisa ser ponto de partida para novos entendimentos da realidade do objeto. O ensaio é a transcendência do óbvio, de tudo o que tende a tornar-se senso comum, pensamento corrente. É tentativa de superação da relação entre tempo e espaço presentes na racionalização de uma realidade. É o pensar sobre algo que experimenta o objeto nas suas múltiplas possibilidades dentro de uma totalidade que não precisa apresentar-se de forma totalmente cognoscível. O ensaio não se utiliza da história, mas a constrói na lógica do seu próprio movimento de pensar o objeto nos imperativos da relação espaciotemporal. A história é que se ergue em face do movimento do ensaísta e não o ensaísta que se constrói antes de pensar o objeto, por estar imerso em contexto histórico. Ensaio e história - como relação de um objeto que caminha pelo tempo, são equânimes e não estão estabelecidos dentro de uma hierarquia mecanicista ou classificadora, tal como ocorre na ciência tradicional. $\mathrm{O}$ objeto de um ensaio, que esteja relacionado ao pensar sobre algum elemento da história, não se subordina à totalidade da história, como mero objeto funcionalizado em determinado contexto que procura dar compreensão à unidade do objeto, que é pertencer ao movimento da razão como ato de reflexão. 
A unidade do ensaio é determinada pela unidade do seu objeto, junto com a da teoria e da experiência que se encarnaram nele. ... Rebela-se contra a ideia de 'obra prima', que, por sua vez, espelha a ideia de criação e de totalidade (Adorno, 1986, p. 181).

A estética do ensaio tem matizes próprios (Benjamin, 1994). Cada forma ensaística se relaciona como estética própria, visto que, se o ensaio não é mera adaptação ou transposição de um sistema pronto e acabado para compreender o objeto, a estética inerente a este mesmo ensaio não se apresenta de forma rígida e única. A estética do ensaio está relacionada à construção do belo, levando em consideração alguns elementos: o todo e às partes; o discurso; aparência e a essência e a lógica. Em relação ao todo e as partes, o "ensaio tem que conseguir que a totalidade brilhe por um momento em um traço escolhido ou encontrado, sem que se afirme que ela esteja presente" (Adorno, 1986, p. 180). Mesmo que exista uma totalidade subjacente, no "ensaio se reúnem, discretamente, em um todo legível, elementos separados entre si e até mesmo contrapostos; o ensaio não erige um travejamento nem uma construção" (Adorno, 1986, p. 177). A contradição entre o todo e as partes não é necessariamente uma oposição ou a anulação lógica. A contradição existente no ensaio é resultado da dialética que existe entre a realidade objetiva e o sujeito que pensa esta mesma realidade. É a lógica da negação da negação, dentro do a priori inerente das categorias espaciotemporais. Em relação à aparência e essência, o ensaio não cai na dicotomia da filosofia moderna, que separa aparência de essência como um fenômeno resultado da limitação do sujeito que observa o objeto. A separação delas está na não possibilidade de conhecer a totalidade por força do pensamento, tal como Adorno (1991) anunciou no texto Atualidade da Filosofia. Para operacionalizar a apreensão do objeto, a razão instrumental separa os elementos constitutivos dele para sistematizar de forma a criar uma lógica compartilhada que possibilite a objetividade em conhecer o objeto. Assim, aparência e essência, na ciência moderna, são pressuposto essencial e elementar para conhecer a realidade. No ensaio, entretanto, essa separação não é rígida e tampouco se apresenta como pressuposto. Aparência e essência têm a mesma origem. $\mathrm{O}$ ensaio não opera, necessariamente, com as mesmas categorias da razão científica, apesar de recorrer a elas, quando é necessário.

O ensaio não requer a comprovação empírica, mesmo que ela possa apresentar-se como elemento de confirmação de pressupostos. Este é reflexão permanente, em que a centralidade da sua força está menos na evidência empírica e mais nos atributos da razão que pensa a realidade. Apesar disso, a razão subjacente ao ensaio não é de caráter instrumental ou mecanicista, ou seja, a razão é a da razão transgressora. A razão do ensaio não pode e não deve limitar-se ao modelo racionalista que se apresentou e imperou na Idade das Luzes.

No ensaio, os procedimentos de coleta e evidenciação do mundo empírico não são o centro de sustentação da sua forma. Todavia, não se nega a importância da evidência empírica como proposição elementar da produção de conhecimento. A força do ensaio está na forma como os procedimentos são questionados e não como eles se tornam verdades inerentes aos resultados que se originam dele. $\mathrm{O}$ autor, na própria atividade de produção, transforma-se em sujeito que cria, mas que também é criado na dinâmica de elaboração do ensaio. Este, como elemento pedagógico de aprender fazendo, adquire autonomia maior na medida em que o autor renuncia à tentativa de chegar a um fim último, uma verdade suprema. $\mathrm{O}$ ensaio é um meio para quem o escreve, assim como deve ser para quem o lê. $\mathrm{O}$ ensaio não exige comprovação empírica, baseada em evidências em dados primeiros. A utilização de dados secundários também não necessita ser apresentada. Assim, a utilização de dados trabalhados estatisticamente ou coletados pelos métodos tradicionais de coleta de dados (entrevistas, questionários, observações participantes etc.) não são relevantes. A utilização de mecanismos de apreensão da realidade baseada em instrumentos de coletas de dados utilizados pelas ciências descaracteriza a sua essência. No ensaio, o empírico já está apreendido pela consciência do ensaísta, e este reflete criticamente sobre o objeto. O objeto presente na consciência representa um segundo momento. Ele na consciência é exposto à experimentação da razão do ensaísta, que procura extrapolar o limite do óbvio. $\mathrm{O}$ caráter do objeto refletido pelo ensaísta está associado à capacidade de estabelecer relações diversificadas entre o ensaísta, o objeto apreendido e outros objetos que possam relacionar-se aos dois primeiros. Assim, o ensaio está "sujeito a erro ...; por sua afinidade com a experiência aberta, ele tem 
de pagar com aquela falta de segurança que a norma do pensamento institucionalizado teme como se fosse a morte" (Adorno, 1986, p. 177).

O ensaio estuda o objeto na sua condição dialética. Desta forma, pensamento e objeto estão em movimento. No ensaio, o empírico é um momento dado, mas que se modifica logo após a primeira apreensão do objeto por parte do ensaísta. A falta de aprisionamento formal do ensaísta com o objeto empírico permite-lhe refletir em todas as direções. O ensaísta pode ainda aventurar-se na compreensão do objeto por associações ou analogias, sem, contudo, render-se ao formalismo da técnica científica tradicional. Não é sem motivo, portanto, que o ensaísta procura compreender a realidade, experimentando as possibilidades de um vir-a-ser do objeto analisado. Assim, o ensaio educa os sentidos que apreendem o objeto, interagindo realidade e razão sem o mecanicismo tradicional com que a ciência acaba enquadrando a consciência dos cientistas. $O$ ensaísta procura proclamar a libertação dos primeiros graus de compreensão do objeto apreendido pela consciência no primeiro momento. As impressões, em muitas situações, são mais importantes que a apreensão dos objetos por meio dos sentidos. $\mathrm{O}$ ensaio liberta a consciência do aprisionamento estabelecido pelos mecanismos do simples empirismo. Não se trata de qualificar a compreensão do objeto por critérios científicos do empirismo, como sendo menos importante do que a forma ensaística. $\mathrm{O}$ ensaísta não desconsidera totalmente o empírico, caindo em uma metafísica sem sentido ou que nega a importância do real como elemento importante para a construção do conhecimento. Apenas o coloca em posição secundária, em face do movimento da razão para compreender o objeto já apreendido. No ensaio o conteúdo influencia mais a forma (formatação, sistematização dos tópicos, sequência dos itens, forma de exposição das ideias, etapas etc.) do que o inverso. A experimentação do ensaio faz com que o conteúdo defina a forma, pois o ensaio não se deve render ao formalismo e à estruturação do conhecimento. Isto não implica em total descaso ou despreocupação com a forma, pois esta afeta o conteúdo, tal como o tamanho e as características físicas de um formigueiro, que afetam o que acontece no seu interior.

O ensaísta não deve primeiro escolher a linguagem (vocabulários, sequenciamento das ideias, estilo etc.) para depois pensar no conteúdo que precisa ser exteriorizado; mas deve fazer com que a linguagem manifeste o que o ensaísta quer refletir sobre o conteúdo. A linguagem como forma, deste modo, rende-se às necessidades de esclarecer o máximo sobre o conteúdo e não o inverso. É por isso que Duarte (1997, p. 81), estudante dos ensaios de Adorno, afirma que

o ensaio opera por coordenação diferentemente da subordinação lógica do procedimento convencional. O resultado desses modus operandi, no qual a tensão entre a forma de apresentação e o que é apresentado cria uma dinâmica própria, é, entretanto, uma construção mais estática na qual se destaca a justaposição.

Desta forma, trata-se apenas de estabelecer a primazia do conteúdo, sem se render à forma, na mera apresentação formal sem conteúdo consistente. O ensaio segue esta orientação. Não se rende à forma, mesmo que esta seja importante para os estabelecimentos de parâmetros essenciais para a construção do conhecimento. A primazia do conteúdo afeta diretamente a objetividade. Nas ciências, em geral, a objetividade é uma das características determinantes na formação do conhecimento. Por meio da objetividade do método adotado, dos procedimentos de coleta, da análise dos dados, dos protocolos que precisam ser seguidos na aplicação em procedimentos específicos, da formatação e apresentação do trabalho final, etc. a ciência constrói um saber socialmente compartilhado. Não se trata de questionar a importância da objetividade da ciência, pois esta por todos os benefícios gerados para a humanidade já justifica a necessidade da criação do conhecimento objetivado. O ponto é não dogmatizar sobre o conhecimento científico como o verdadeiro, o único correto ou o melhor. O ensaio permite que o ensaísta apresente fragmentos de pensamentos, reflexões iniciais e parciais, sem cair na necessidade de apresentar um sistema completo de pensamento. Assim, o ensaio se aproxima das manifestações rápidas da consciência, do intuitivo como característica relevante para a formação do conhecimento. A objetividade sistematizada, como se apresenta na ciência, por exemplo, cede espaço às reflexões rápidas e baseadas em componentes associadas à subjetividade do ensaísta, o que não implica associá-lo a uma aventura meramente subjetiva. 
A objetividade não está no método, como ocorre na ciência, mas na surpresa que o ensaio provoca em quem o lê. A objetividade não acontece na formalidade de se aceitar um método consolidado e validado por sucessivas repetições sistematizadas de um procedimento. Ela consiste inicialmente no reconhecimento da originalidade do ensaio por parte daqueles que o leem. Desta forma, a objetividade é desnudada do formalismo burocratizante da ciência. A objetividade do ensaio não está associada exclusivamente à construção de um sistema racional compartilhado e que se reifica com o tempo devido à natureza afirmativa da ciência. O ensaio tem como característica não cair em dogmas de natureza afirmativa. $\mathrm{O}$ fato é que a objetividade do mundo contemporâneo leva a uma racionalidade limitada, de compreensão de um espectro reduzido ao sensível e baseado na aparência do fenômeno. O ensaio, anterior ao estabelecimento da ciência com critérios extremos de objetividade, procura fugir dessa lógica. Apesar de trabalhar com a ideia que o objeto existe independentemente do sujeito, pois o próprio ensaio é a prova disso, o mesmo constrói a objetividade no próprio processo de conhecer o objeto. Este processo de construir o conhecimento serve, posteriormente, como elemento de surpresa para aqueles que leem o ensaio. A legitimação do ensaio está na aceitação daqueles que os leem e independentemente de concordarem ou não, o legitimam por reconhecerem sua originalidade e demais características, por meio da integração e envolvimento na construção do conhecimento, durante o processo de interação do ensaísta com o objeto do ensaio. Esta não ocorre como acontece nos grupos fechados, cuja burocracia atual instituiu a ciência. Isto implica afirmar que não são somente os pares de uma mesma área de conhecimento ou da mesma especialidade que reconhecem se um ensaio é digno de validade ou legitimidade, mas é o conjunto amplo de indivíduos e coletivos que dão legitimidade ao ensaio, quando este é reconhecido como influente e importante no processo de reflexão sobre o que o ensaio se propõe a pensar.

O ensaio adquire sua legitimação no conjunto dos indivíduos, independentemente da área de conhecimento ou especialidade. Exemplo disso são os ensaístas que pensaram sobre a importância de conhecer, por verificação imediata do objeto em si, o que acabou por formar o empirismo. O empirismo não é um conhecimento legitimado apenas por um conjunto de filósofos ensaístas (Bacon, Locke, Hume, Hobbes, etc.), os quais refletiram sobre sua importância para conhecer a realidade, mas também refletiram por todos os indivíduos que se interessam pela epistemologia e trabalham em áreas e especialidades diversificadas: física, química, educação, ciências sociais, administração, economia etc.

No ensaio, um objeto existe por si só, ou seja, é uma coisa-em-si. Mesmo que este objeto não seja concreto ou material e verificável, porque se pode pegá-lo. O que importa no ensaio é que o objeto pode ser concreto ou não, material ou imaterial ou ainda imaginário. A condição apenas é que este seja real. Assim, um objeto pode ser algo objetivo para o ensaísta e para outras pessoas, estar associado a mais profunda subjetividade do sujeito; mas o que importa é que ele seja real por se apresentar como um vir-a-ser cognoscível, mesmo para um número reduzido de indivíduos. O objeto aparece como fenômeno, isto é, apresenta-se como coisa-para-si. O fenômeno é resultado de um objeto que adquire propriedades específicas por simplesmente interagir com o imediatamente dado: as demais coisas-em-si que existem e estão presentes no contexto do objeto. Os fenômenos, assim, aparecem como o objeto que está interagindo em um contexto imediatamente dado, além de já adquirir propriedades de quem observa o fenômeno. Neste caso, o ensaísta, com suas condições sensíveis, seus sistemas, mesmo que mínimos, de interpretação, sua racionalidade, sua contextualização como indivíduo que está imerso também no imediatamente dado.

O fenômeno é, portanto, resultado de um para-si, formado no indivíduo que o presencia dentro do contexto imediatamente dado. Todavia, o indivíduo não vivencia o fenômeno isoladamente. Na interação com o contexto imediatamente dado, nas suas condições sensíveis, nos sistemas de interpretação formulada e na racionalidade do ensaísta, há a presença do social como condição mediata ou imediata que está presente, concreta ou abstratamente presente. Nestas condições o ensaio se insere e por elas ele se aproxima mais da arte do que a ciência, por ser um meio de autonomia do ensaísta, sem, contudo, colidir com o social. No ensaio, o ensaísta não se divorcia da sua subjetividade em favor da objetividade da ciência; apenas se conforma no contexto imediatamente dado. O ensaísta não precisa renunciar a tudo em favor da objetividade ou da originalidade, pois ambas são construídas a 
partir da interação do ensaísta com seu objeto e no movimento do próprio ensaio. Outro pressuposto no ensaio é que um fenômeno não é um fato. Este equívoco é comum: achar que um fenômeno por si só se constitui um fato. Um fato é um fenômeno pensado e consolidado com propriedades que provam a existência do acontecimento propriamente dito. A temporalidade, assim, é um dos elementos intrínsecos aos fatos. Outra é a presença do social que legitima como real o que acaba de acontecer. Desta forma, um fato pode ser identificado e verificado por qualquer um (indivíduo ou coletivo), que disponha dos meios adequados para identificá-lo e compreendê-lo como real. Os fatos geralmente adquirem propriedades qualitativas e quantitativas, podendo, desta forma, ser descritos ou previstos por meio de aferições.

Os fatos na ciência moderna só existem devido à existência de instrumentos ou esquemas de interpretação que os objetivam e possibilitam criar generalizações. Os fatos na pesquisa científica, em muitas situações, indicam os objetos que serão analisados. Podem também sustentar as afirmações como forma de argumentos ou de comprovação. Em Kant a noção de fato aproxima-se tanto da noção de fenômeno como de elemento ou condição da razão. Em todas as situações, ele está associado à experiência e fundado em uma realidade com certas conexões causais. No ensaio, os fatos não são mais do que elementos que são incorporados no processo de construção do objeto. Este pode ser o ponto de partida de um ensaio, mas os mesmos fatos não podem ser pontos de chegada. O imperativo do ensaio é a transformação e os fatos são modificados juntamente com o movimento do ensaísta. Os fatos não são tidos como verdades. Sua utilidade, como prova ou como objeto, é relativa no ensaio.

Os fatos são abandonados como verdades no momento posterior à sua apropriação pelo ensaísta. Eles não servem como momentos afirmativos ou de comprovações cegas de determinadas realidades. Os fatos geram a própria desconfiança que o ensaísta precisa fazer perdurar em sua construção. $\mathrm{O}$ ensaísta atribui ao fato o caráter de fenômeno pensado por conceitos; por isso o fato não é o princípio da verdade. Todo ensaísta tem como pressuposto pensar a partir de conceitos, que são esquemas de interpretação. Estes conceitos estão em constantes modificações, pois a realidade muda, assim como o ensaísta muda na realização do seu ensaio. Desta forma, o conceito é todo processo que torna possível a descrição, a classificação e a previsão dos objetos cognoscíveis. O conceito é formado a partir de uma rede simbólica complexa (organizada de forma inteligível), relacionada à intencionalidade do sujeito em conhecer. O conceito não é meramente essência e não é simplesmente signo.

No ensaio, "todos os seus conceitos devem ser expostos de tal modo que uns carreguem aos outros, que cada um se articule segundo as suas configurações com outros." (Adorno, 1986, p. 177). Este movimento dialético articula conceitos para compreender a realidade, da mesma forma que neste movimento faz colidir os diversos conceitos que inicialmente teriam apenas relação remota. Na elaboração do ensaio, o ensaísta aproxima ou afasta sistematicamente os conceitos com a finalidade de dar significado para a realidade, seja pelo rompimento do padrão de compreensão seja para a confirmação dele. $\mathrm{O}$ fato é que o conceito entra no movimento da realidade e do pensamento do ensaísta. Todavia, esta apropriação dos conceitos pelo ensaísta não ocorre de forma sistemática ou organizada, não da forma como a ciência geralmente utiliza ou articula os conceitos. A forma subjetiva como o conceito pode ser introduzido no ensaio contrasta com o formalismo que a ciência faz questão de apresentar em todas as etapas dos seus procedimentos. Enquanto a ciência introduz a condição da objetividade do início ao fim de uma pesquisa, o ensaio trabalha dialeticamente com a relação subjetividade-objetividade, em movimento permanente de afirmação e renúncia ao caráter afirmativo que o conhecimento pode adquirir no movimento do pensamento. $O$ ensaio faz do movimento dos conceitos uma arma contra a reificação do ensaísta no processo de construção do conhecimento, ao contrário do que a ciência tradicional procura fazer com a utilização dos conceitos, isto porque é "mera superstição da ciência propedêutica que os conceitos seriam em si indeterminados e que só seriam determinados através de sua definição" (Adorno, 1986, p. 176).

No ensaio, a linguagem não é maior que o conceito. É forma de concretização do pensamento, mas não prisão que inviabiliza pensar para além do que realmente um conceito quer afirmar. Nem todos os conceitos precisam prender-se as regras formais da linguagem, pois o ensaísta, em pouco tempo, abandona o conceito imediatamente criado, para nova formulação conceitual derivada do primeiro. Neste ínterim, a linguagem e os formalismos da razão instrumental, inerentes a ela, são 
abandonados. Da mesma forma que absorve "conceitos e experiências de fora, assim também absorve teorias. Só que a sua relação com elas não é a do ponto de vista" (Adorno, 1986, p. 182). A teoria, na ciência tradicional, expressa um conjunto de conceitos sistematicamente organizados e articulados, para criar um contexto cognoscível. Assim, a teoria apresenta-se como a expressão manifesta do pensar reificado, com conceitos baseados em fatos apresentados sistematicamente, de forma que sejam inteligíveis. Desta forma, a teoria tradicional, associada à ciência tradicional, é cognoscível, pois pressupõe o princípio da identidade. No ensaio, a teoria nem sempre ocorre por racionalização ou demonstração, mas pelo princípio da não-identidade. Esta diferença causa estranhamento aos cientistas ou usuários de abordagens tradicionais das teorias. Tal estranhamento ocorre devido à recusa da possibilidade que o princípio da não-identidade é capaz também de resultar em uma forma de compreensão da realidade. Analogamente, é como aceitar que um surdo possa compor uma sinfonia. $\mathrm{O}$ ensaio não se utilizaria do som, como a ciência, baseada na teoria tradicional, se utilizaria para fazer uma sinfonia. Mas, assim como Beethoven foi capaz de utilizar-se de outros sentidos para compor suas sinfonias, o ensaísta utiliza-se de outros meios também para construir novas compreensões da realidade. Após vivenciar a forma tradicional de criar conhecimento por meio das racionalidades consolidadas, ele procura reorganizar os sentidos, as faculdades responsáveis pela articulação do pensamento e as convicções intelectuais para compor nova compreensão da realidade, fora desta do mean stream.

A teoria adquire o caráter não dogmático de verdade, movimento tradicional que ocorre nas teorias científicas. A relação do ensaio com a teoria, assim como na relação entre conceito e ensaio, impera a não-identidade. No ensaio, o pensamento liberta-se da ideia tradicional de verdade (Adorno, 1986). O pensamento ganha autonomia por ser algo inerente ao ensaísta. No contexto do ensaio, o pensamento ganha autonomia justamente por permitir que a subjetividade do ensaísta ganhe força e importância na ação de compreender o objeto colocado em análise. O ensaísta ocupa seu espaço como sujeito de pensamento autônomo, que não renuncia à autonomia exatamente por não se render aos métodos e sistemas que tentam objetivar totalmente a realidade. $\mathrm{O}$ ensaísta procura trazer o leitor para o universo do ensaio, permitindo a relação da sua subjetividade com a do leitor. Os espaços não se consolidam como arenas de disputas pela razão baseada em verdades provadas por fatos e evidências. $\mathrm{O}$ ensaio permite que os sujeitos relacionados a ele desenvolvam sua autonomia intelectual e formem seu próprio conhecimento, sem cair na racionalidade totalitária, que tende a enquadrar a compreensão da realidade a partir do estabelecimento de verdades aparentes. Por este motivo, o ensaio não necessita apresentar conclusões afirmativas. Os questionamentos, em forma de reflexões e de novas perguntas, são mais relevantes do que conclusões que estabelecem o marco final e definitivo. A lógica do início, meio e fim não segue a regra dos projetos de pesquisas tradicionais. A formalidade da sistematização racionalizada cede em face do movimento permanente de reflexão, que se constrói a partir da relação dúvida, pergunta, reflexão, identidade, não-identidade e nova dúvida. O movimento do ensaio pode seguir essa lógica, sem cair no mecanicismo de ser a única forma de se estabelecer a construção de compreensões do objeto. No ensaio é mais relevante estabelecer as dúvidas certas do que chegar às afirmações tidas como verdadeiras. A importância de estabelecer perguntas adequadas garante a relação dialética entre subjetividade e objetividade.

No ensaio, não é preciso uma conclusão no sentido tradicional; cada parte é uma conclusão por si mesma. No desenvolvimento do ensaio, são geradas as próprias conclusões para as reflexões anunciadas inicialmente em forma de questionamentos. Assim, esta parte do ensaio não é uma conclusão no sentido tradicional; apenas direciona a reflexão para pensar a realidade do ensaio como forma na administração. Ensaio não é estudo teórico, baseado em revisões teóricas que, posteriormente, vão amparar pesquisas empíricas ou reflexões conceituais, formatadas dentro da divisão clássica da ciência. Existe equívoco, quando é atribuído o nome de ensaio-teórico para estudos que se caracterizam como estudos teóricos. Este equívoco tornou-se quase regra, chegando a ser institucionalizado nos programas de pós-graduação e pesquisa em administração, assim como nas associações especializadas da área de administração. Ensaio também não é forma facilitada de produção científica, em que é exigida apenas a razão do escritor, a partir da escolha do tema. $\mathrm{O}$ ensaísta precisa transgredir a forma convencional e tradicional de pensar a realidade, pois só assim pode gerar conhecimento original e diferenciado. O ensaísta é antes de tudo experimentador e não 
reprodutor de conhecimento ou produto de reflexões presas à formalidade do método. Por meio do ensaio, a administração deve possibilitar um vir-a-ser, ou seja, elo entre o conhecimento existente e novo, baseados na originalidade.

O ensaio na administração possibilita a transgressão lógica, tão importante para o rompimento com a razão tradicional, alicerce da ciência tradicional. Os ensaístas da administração são convidados à experimentação do objeto por meio da reflexão negativa, com o princípio da não-identidade. $\mathrm{O}$ ensaio convida também o leitor da área a participar dele. Na medida em que o leitor o lê, ele por si só reflete a realidade motivada pelas concordâncias e discordâncias dos argumentos desenvolvidos. Por meio do ensaio, o leitor é provocado e mobilizado na sua subjetividade, para concordar ou discordar com o movimento reflexivo que ocorre no percurso da leitura. Nele não há o deslumbramento, que induz o leitor à ilusão, mas o movimento de criar a sensação de desconforto e insatisfação com o que o leitor se depara ao longo da leitura. No ensaio, há forma própria de relacionar a subjetividade do ensaísta com a objetividade da realidade como algo que existe em si mesmo. As subjetividades são convidadas a vivenciar o processo de objetivação, sem fazer com que alguém renuncie às suas particularidades. Em áreas como a administração esse processo é visto com desconfiança; para leitores cujas consciências já foram dominadas pelo método tradicional de fazer ciência esta forma de conhecimento é vista com preconceito. O fato é que a realização de um ensaio, em muitas situações, exige mais esforços do que o método científico de fazer ciência, visto que, sem as devidas caracterizações descritas anteriormente, não se pode atribuir a qualidade de ensaio a um conjunto de conceitos, teorias, argumentos etc.

Na administração em que o imperativo da objetividade domina a produção de conhecimento, o ensaio é importante recurso para ampliar a interdisciplinaridade e promover a construção de saberes por meio da relação intersubjetiva. Todavia, há dificuldades visíveis, devido à tendência totalitária em acreditar que o método científico é o único que pode levar à administração o verdadeiro conhecimento. $\mathrm{E}$ você, leitor, este ensaio sobre o ensaio causou-lhe desconforto suficiente para fazê-lo lançar-se a realização de um ensaio?

\section{Notas}

\footnotetext{
${ }^{1}$ A partir deste momento, o termo ensaio-teórico será mencionado apenas com a nominação ensaio.

2 "A consciência da não-identidade entre o modo de expor e o objeto impõe ilimitado esforço à exposição. Isso, e só isso é que no ensaio é semelhante à arte; fora disso, o ensaio está necessariamente aparentado com a teoria, por causa dos conceitos que nele aparecem e que trazem de fora não só seus significados, mas também o seu referencial teórico. É claro que o ensaio se comporta, em relação à teoria, tão cautelosamente quanto em relação ao conceito. O ensaio não deriva sem rodeios da teoria, pecado cardeal de todos os últimos trabalhos ensaísticos de Lukács, nem pode ser pagamento em prestações sobre sínteses vindouras" (Adorno, 1986, p. 181).
}

\section{Referências}

Adorno, T. W. (1986). O ensaio como forma. In G. Cohn (Org.), Sociologia: Adorno (pp. 167-187). São Paulo: Editora Ática.

Adorno, T. W. (1991). Actualidad de la filosofía [Coleção Pensamiento Contemporáneo]. España, Barcelona: Ediciones Piados.

Bachelard, G. (1998). A água e os sonhos: ensaio sobre a imaginação da matéria. São Paulo: Martins Fontes. 
Benjamin, W. (1994). Magia e técnica, arte e política: ensaios sobre literatura e história da cultura (7a ed.). São Paulo: Brasiliense.

Bense, M. (1947). Ünber the essay und saine prosa. Berlin: Merkur I.

Boorstin, D. J. (1995). Os criadores. Rio de Janeiro: Civilização Brasileiro.

Duarte, R. (1997). Adornos: nove ensaios sobre o filósofo frankfurtiano. Belo Horizonte: Ed. UFMG.

Habermas, J. (2001). A constelação pós-nacional: ensaios políticos. São Paulo: Littera Mundi.

Hume, D. (1996). Investigação acerca do entendimento humano [Coleção Os Pensadores]. São Paulo: Nova Cultural.

Locke, J. (1997). Ensaio acerca do entendimento humano [Coleção Os Pensadores]. São Paulo: Nova Cultural.

Lukács, G. (1911). Die seele und die formen. Berlim: Merkur.

Montaigne, M. (2002). Os ensaios, Livro I. São Paulo: Martins Fontes.

Rousseau, J. J. (1973). Ensaio sobre a origem das línguas [Coleção Os Pensadores]. São Paulo: Abril Cultural. 